\title{
Application of Jute Fiber in Soil Stabilization
}

\author{
Shwetha Prasanna*1, Nevil Macedon Mendes \\ Associate Professor ${ }^{1}$ and Student ${ }^{2}$ \\ Department of Civil Engineering, Don Bosco College of Engineering, Fatorda, Goa, India \\ *shwethaprasanna@gmial.com, shwetha.p@dbcegoa.ac.in
}

\begin{abstract}
This paper is focusing on the stabilisation of soil using jute fibre as soil stabilizer. Stabilisation is the process of modifying the properties of a soil to improve its engineering performance and used it for a variety of engineering works. This study examines the potential of soil stabilization with jute fibre when it is cut into roughly $30 \mathrm{~mm}$ lengths as stabilizer. The varying percentages like $0.5 \%, 1 \%, 1.5$ and $2 \%$ of pieces of jute fibre were used and mixed it with soil. The laboratory tests such as California Bearing Ratio (CBR) test, modified compaction tests and direct shear strength tests have been conducted to observe the change in engineering properties of soil. On the basis of the experiments performed, it can be concluded that the stabilization of soil using $30 \mathrm{~mm}$ pieces of jute as stabilizer improves the strength characteristics of the soil so that it becomes usable as one of the reinforcing material for the construction of roadways, parking areas, site development projects, airports and many other situations where sub-soils are not suitable for construction.
\end{abstract}

Keywords: jute fibre; reinforcement; modified compaction test; California bearing ratio test; stabilization; shear strength

\section{Introduction}

Geotechnical materials can be developed by reinforcing soil with short and randomly spread fibrous materials (Kumar \& Sharma, 2018). This technique has proven its efficiency, especially with regard to the mechanical behavior of the resulting material. In the modern history of soil stabilization, the concept and principle of soil reinforcement was first developed by Vidal (1969). He demonstrated that the introduction of reinforcing elements in a soil mass increases the shear resistance of the medium. Consequently, efforts for using fibrous materials, such as natural fibers, coconut (coir) fiber, sisal, palm fibers, jute, flax barely straw, bamboo and cane as reinforcing elements were stated. Many studies reported that the inclusion of fibers in a soil matrix, primarily with fine grains, raises the shear resistance of the material (Donato et al., 2004, Babu \& Vasudevan, 2008, Maliakal \& Thiyyakkandi, 2013, Mohamed, 2013). The performance of a soil-fiber mixture depends not only on the individual properties of the constituents, but also on the compatibility between the fibers and soil. The interface between reinforcement and matrix constitutes the contact area of the elements in the blend and is essential for the transmission of mechanical tensions from the matrix to the reinforcement (Tang et al., 2010). From the economical point of view, in an ideal conditions the cost of conventional structure may be reduced up to $50 \%$. There are several examples of reinforcing the soil like "great wall of China (earliest example of reinforced earth using branches of trees as tensile materials), ziggurats of Babylon (woven mats of read were used) etc. In USA \& Europe, the erosion \& stability of slopes for highway and railway embankment is controlled using reinforced soil.

Soil reinforcement technology aims to improve the engineering properties of soil to enhance slope, pavement, embankment, and landfill stability (Kim et al. 2015). Geosynthetics, such as geogrid, geotextile, geonet, and geocell, are traditional reinforcement materials. They can be varied in forms (e.g., strips, bars, grids, sheets, etc.) and in mechanical properties (e.g., texture, stiffness, and density). They are often introduced to structures in different layers with a predetermined orientation (Maher and Gray 1990). However, potential weak planes can develop along the geosynthetics-soil interface due to lower interfacial shear strength. Regardless, geosynthetic-reinforced materials have been proved useful in some applications (Leshchinsky et al. 1997, Patra et al. 2005, Han et al. 2012). Compared with traditional geosynthetic reinforcement methods, soil reinforced with discrete short fibers is easier to prepare and can maintain strength isotropy without introducing the potential of weak planes 
(Chakraborty and Dasgupta 1996, Yetimoglu and Salbas 2003, Ahmad et al. 2010). More importantly, this kind of reinforced soil is effective in improving the shear, compressive, tensile, liquefaction strength, California Bearing Ratio (CBR) value, bearing capacity, freezing-thawing behavior, and wetting-drying cycles, and for reducing the swelling tendency, brittleness, and desiccation cracking. Shwetha Prasanna and Prasanna Kumar (2017) carried out a research on soil reinforcement using coconut shell ash as waste material for Indian soil. They observed that at $0.8 \%$ of coconut ash achieved maximum improvement of MDD and OMC and they also concluded that angle of internal friction and cohesion was achieved at the range of 0.4 to $0.8 \%$. Shwetha Prasanna (2018) utilized waste plastic shreds for stabilization of soil. In this paper author added waste plastic shreds in varying percentages like $2,4,6,8$, and $10 \%$ to the soil samples. Author concluded that there was a decrease in MDD, $\mathrm{OMC}$, and cohesion and a slight increase in friction with an increase in the percentage of reinforcement. The decrease in maximum dry density of soil must be due to low specific gravity of plastic shreds. Among various types of fibers used as soil reinforcement materials, natural fibers, such as coir, sisal, palm, jute, flax, and so forth, are inexpensive, available, biodegradable, and provide excellent reinforcement effects (Prabakar and Sridhar 2002, Segetin et al. 2007, Anggraini 2016, Wang et al. 2016). Of all the natural fibers, jute has the highest tensile strength and can resist both rolling and heat.

In the present study jute fiber is used to improve the engineering properties of the soil. Accordingly, this study evaluates the potential of using jute fibers to improve the changeable compaction, shear strength and CBR of soil. In this study a Proctor Compaction test, direct shear test and California Bearing Ratio tests have been carried out on soil mixed with jute fiber. Jute fibers of length $30 \mathrm{~mm}$ are mixed with soil in different percentage $(0.5,1.0,1.5$, and $2 \%)$ to find out the optimal quantity. Proctor, direct shear and CBR test results are presented in the paper.

\section{Materials and Methodology}

The soil samples used in this study were obtained as undistributed samples collected from PondaMargao highway, Tolar area, Borim. The study area Falls under the district of South Goa in the Taluka of Salcete. All samples were taken from Tolar area at 3 different points. The coordinates of Tolar area are $15^{\circ} 20^{\prime} 23.2^{\prime \prime} \mathrm{N}$ and $74^{\circ} 00^{\prime} 02.9^{\prime \prime} \mathrm{E}$. The jute fibres were procured from the local market in the form of gunny bags (Hessian formed from jute) which were then loosened and cut in lengths of approximately $30 \mathrm{~mm}$. In this paper experimental study on the effect of jute fibre to increase the strength of the soil was studied. Different tests were conducted on soil sample with varying percentage of jute fibre. The samples were subjected to different laboratory tests such as particle size distribution (wet sieve analysis), Atterberg's limits, compaction tests, direct shear tests and California Bearing ratio tests.

\section{Results and Discussion}

\section{Unreinforced Sample}

Sieve analysis tests (wet analysis) were performed on the unreinforced soil samples. Based on the sieve analysis it was concluded that the soil was belongs to 'poorly graded' type soil. Atterberg's limits tests were performed on unreinforced soil samples. The results obtained were as follows; the Liquid limit (LL), Plastic limit (PL) and Plasticity index (PI) were 34.6\%, 25.27\% and 8.94. The results are shown below. 


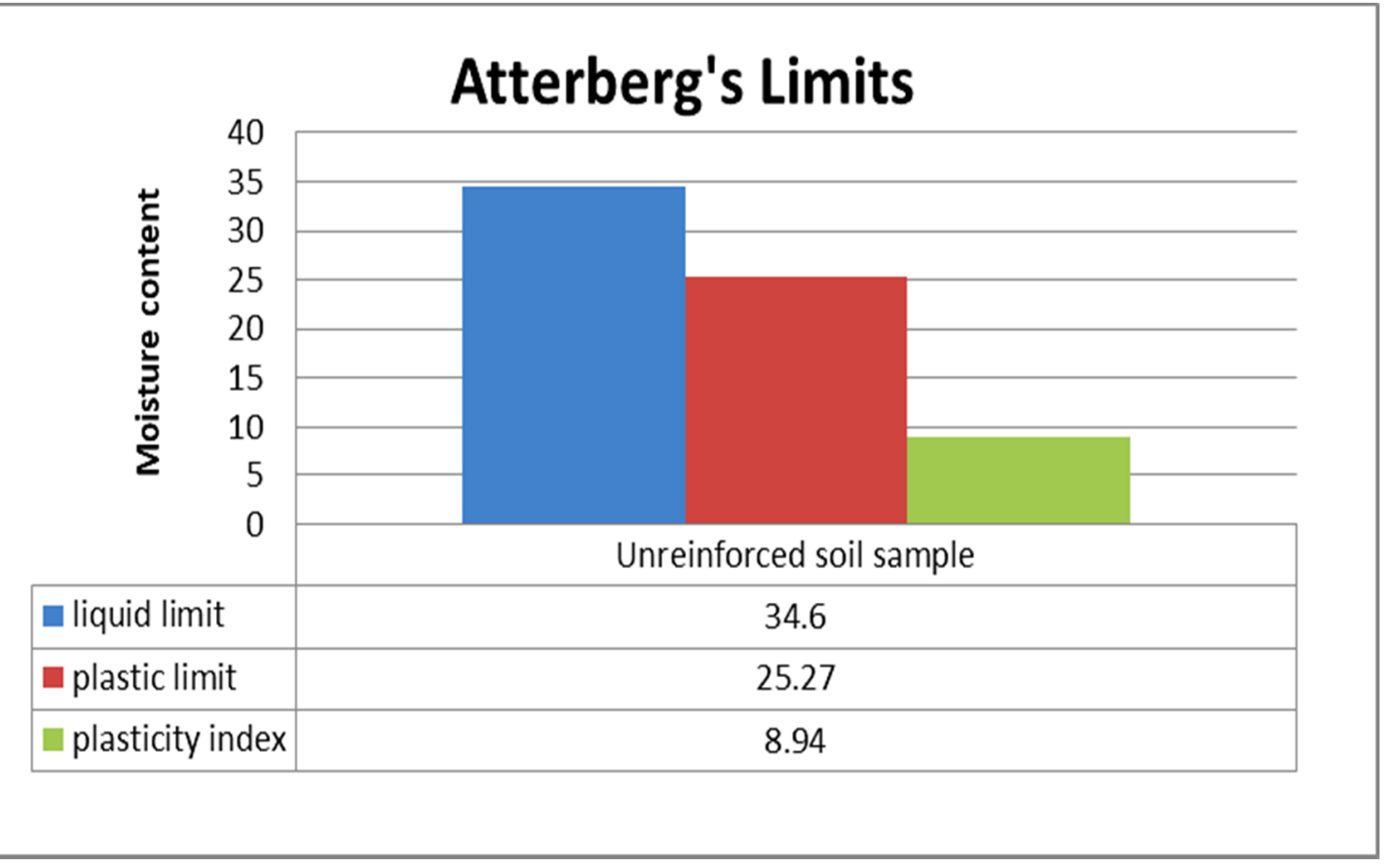

Figure 1: Atterberg limits for unreinforced sample

Then modified proctor test was performed to observe the maximum dry density (MDD) and optimum moisture content $(\mathrm{OMC})$ on unreinforced soil samples. The tests were performed by taking $5 \mathrm{~kg}$ of unreinforced soil samples and water was added to it starting from $10 \%$ by total dry weight of unreinforced soil sample and later on with an increment of $2 \%$ water content. It was found that the maximum dry density (MDD) of $1.90 \mathrm{~g} / \mathrm{cm}^{3}$ and optimum moisture content (OMC) of $16 \%$ and then later on at $18 \%$ moisture content the MDD dropped from $1.90 \mathrm{~g} / \mathrm{cm}^{3}$ to $1.86 \mathrm{~g} / \mathrm{cm}^{3}$ which showed that the soil being unreinforced could be well compacted at an OMC of $16 \%$.

$\operatorname{MDD}\left(\mathrm{g} / \mathrm{cm}^{3}\right)$ at various percentages of jute fibers

OMC (\%) at various percentages og jute fibers
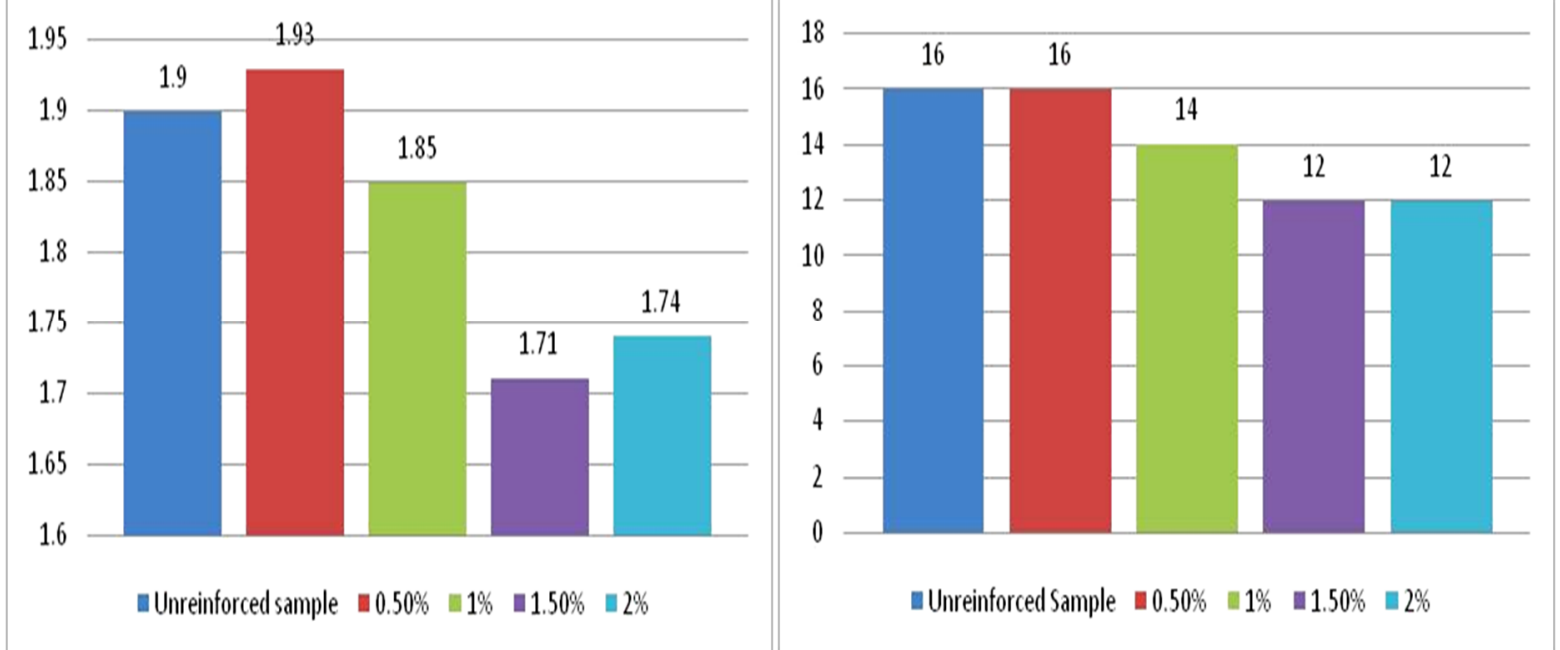

Figure 2: Comparison of MDD and OMC for different percentages of jute fibers 


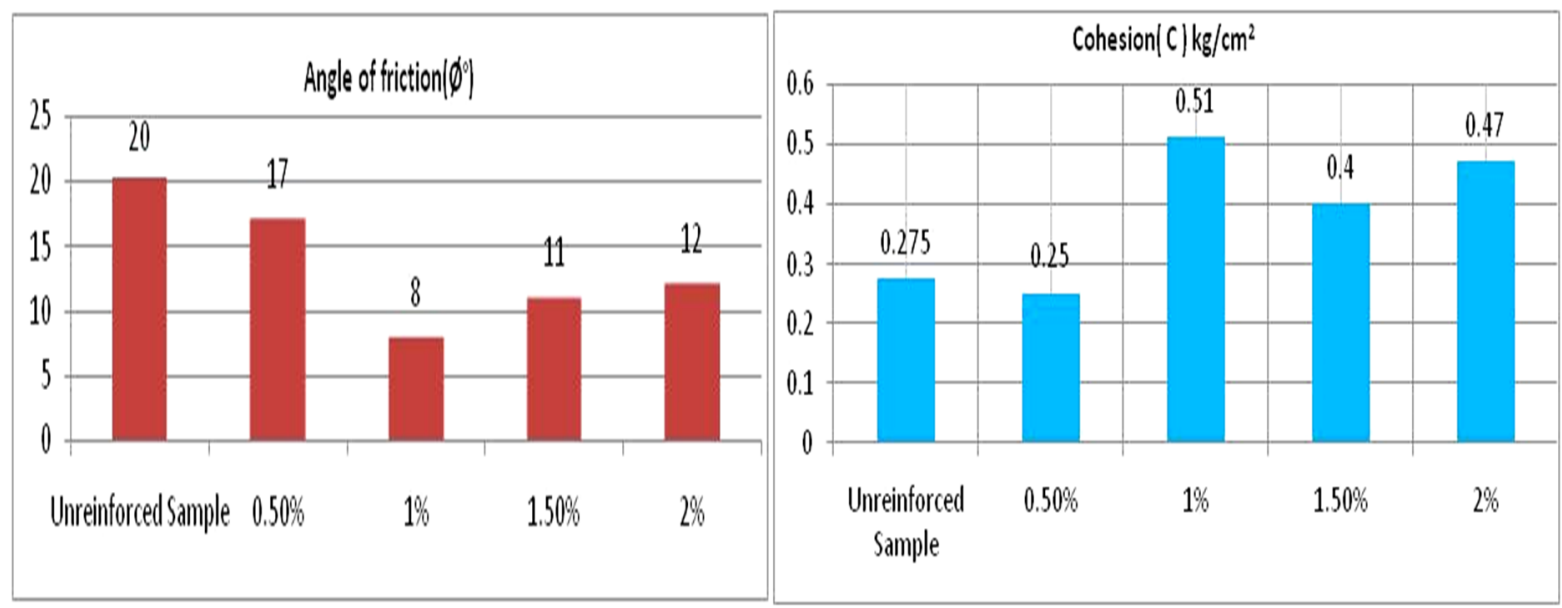

Figure 3: Comparison of friction and cohesion for different percentages of jute fibers

Next, direct shear tests were conducted to determine the shear strength parameters which is cohesion(C) and angle of friction (Ø) of unreinforced soil samples. The tests results conducted for unreinforced soil samples showed that the cohesion (C) value obtained was $0.275 \mathrm{~kg} / \mathrm{cm}^{2}$ and the angle of friction (Ø) obtained was $20^{\circ}$.

At last, California Bearing Ratio tests were conducted (as per IS 2720 (Part 16):1987) on unreinforced soil samples. For this test, the observations were observed at $2.5 \mathrm{~mm}$ penetration and at $5 \mathrm{~mm}$ penetration. It is to be noted that if the penetration of soil sample at $2.5 \mathrm{~mm}$ is greater than that at $5 \mathrm{~mm}$ than the former is to be adopted as the CBR of the soil sample; but if the penetration at $5 \mathrm{~mm}$ is greater than that at $2.5 \mathrm{~mm}$ then the latter is to be adopted provided the test has been repeated for the said results. The CBR results for the unreinforced soil samples were as follows, at $2.5 \mathrm{~mm}$ penetration the CBR value was $28.19 \%$ and at $5 \mathrm{~mm}$ penetration the CBR value obtained was $26.19 \%$, hence the CBR of unreinforced soil sample was $28.19 \%$ at $2.5 \mathrm{~mm}$ penetration.

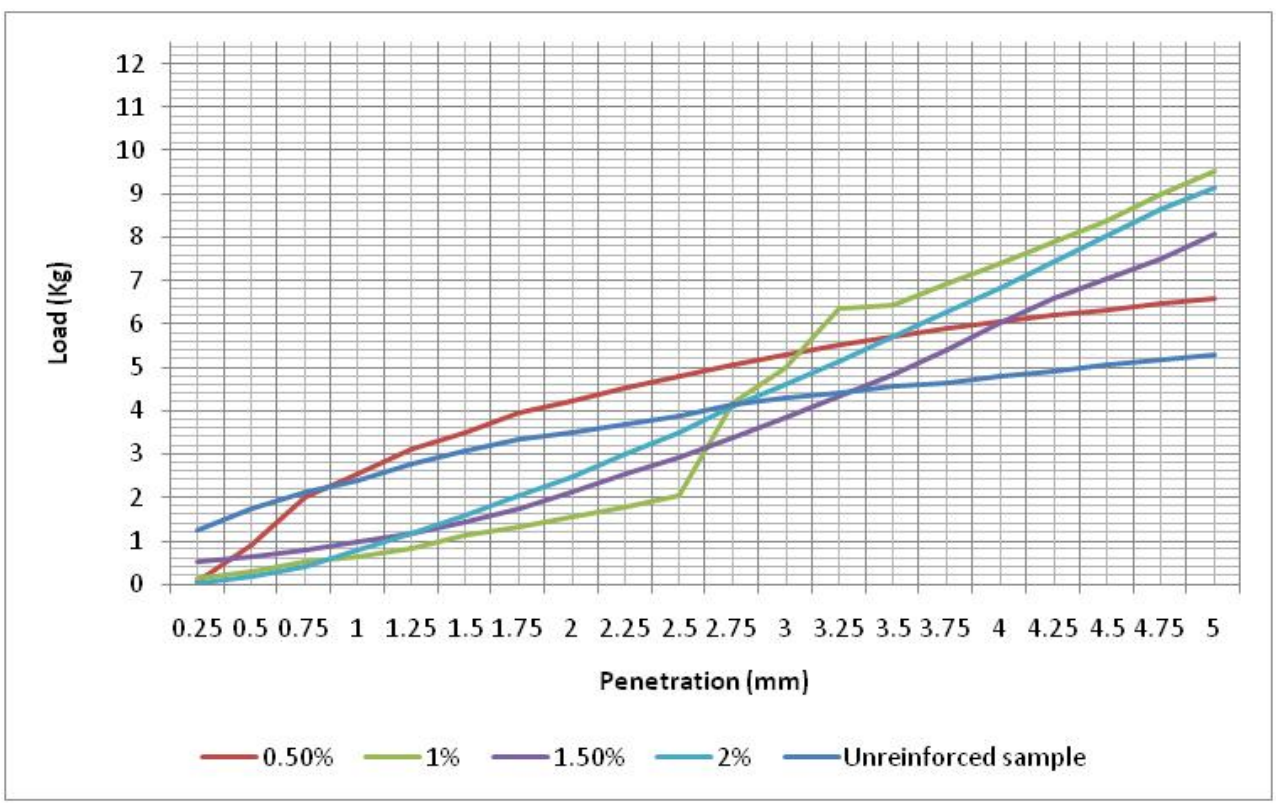

Figure 4: Comparison of CBR values for different percentages of jute fibres 


\section{Reinforced Soil Sample}

To ascertain the effects and change in behaviour of soils subjected to jute fibres, soil samples were subjected to varying percentages of jute fibres as reinforcement. These samples were tested by conducting tests such as modified proctor test, direct shear test and California Bearing Ratio test.

Modified proctor test was conducted on reinforced soil samples at varying percentages of jute fibres of $0.5 \%, 1 \%, 1.5 \%$ and $2 \%$. The results obtained were as follows; by referring the graph in figure 2 , for soil sample reinforced with $0.5 \%$ jute fibre, the MDD obtained was $1.93 \mathrm{~g} / \mathrm{cm}^{3}$ at an OMC of $16 \%$. This shows that after addition of $0.5 \%$ jute fibre there is a positive improvement in MDD and OMC, that is, an increase in $1.55 \%$ in MDD and at the OMC of $16 \%$. Again, after addition of $0.5 \%$ of jute fibre, that is $1 \%$ in jute total of jute fibre, the MDD obtained was $1.85 \mathrm{~g} / \mathrm{cm}^{3}$ and $\mathrm{OMC}$ was $14 \%$. This showed that after addition of $1 \%$ jute fibre the MDD did reduce slightly by $4.44 \%$ but OMC reduced considerably by $2 \%$. For $1.5 \%$ of jute fibre, MDD again reduced to $1.71 \mathrm{~g} / \mathrm{cm}^{3}$ at an $\mathrm{OMC}$ of $12 \%$. For $2 \%$ jute fibre, MDD again reduced slightly to $1.74 \mathrm{~g} / \mathrm{cm}^{3}$ at an OMC of $12 \%$. By comparing the results obtained from the graphs it could be concluded that at $0.5 \%$ of jute fibre, maximum improvement of MDD and OMC for poorly graded type soil was achieved. Fiber-reinforcing effects are more pronounced at lower water content and higher dry density mainly due to a greater effective contact area and the weaker waterlubricating effects of the fiber-soil interface.

Next, direct shear tests were conducted for soil samples reinforced at varying percentages of jute fibre of $0.5 \%, 1 \%, 1.5 \%$ and $2 \%$ to determine the strength parameters of reinforced soil, which is cohesion(C) and angle of friction(Ø). Generally, higher the $\varnothing$ and $C$ values better is the shear strength of the soil and also the stability of the slope. The results obtained were as follows; by referring the graph in figure 3, for $0.5 \%$ jute fibre $C=0.25 \mathrm{~kg} / \mathrm{cm}^{2}$ and $\varnothing=17^{\circ}$ values were obtained. Here, the cohesive value reduced slightly by $9 \%$ while the angle of internal friction reduced a bit by $2^{\circ}$. For $1 \%$ jute fibre, the values of $\mathrm{C}=0.51 \mathrm{~kg} / \mathrm{cm}^{2}$ and $\varnothing=8^{\circ}$; here the cohesive value showed a positive improvement of $50 \%$ increase as compared $0.5 \%$ jute fibre sample while internal angle of reduced by $9^{\circ}$. For $1.5 \%$ jute fibre, the $\mathrm{C}=0.4 \mathrm{~kg} / \mathrm{cm}^{2}$ and $\varnothing=11^{\circ}$ were obtained. Here, a reduction in the cohesion value as well as angle of friction was observed. For $2 \%$ jute fibre, $\mathrm{C}=0.47 \mathrm{~kg} / \mathrm{cm}^{2}$ and $\varnothing=12^{\circ}$ were obtained; the cohesion value here slightly increased by $14 \%$ as compared to the previous percentage of jute fibre whereas the angle of friction also increased $1^{\circ}$ as compared to the previous percentage of fibre. Hence, as seen from the figure 3, it could be concluded that, maximum improvement in shear strength that is cohesion(C) and angle of friction $(\varnothing)$ of soil was observed between $1 \%$ to $2 \%$ of jute fibre as reinforcement.

Next, California Bearing Ratio tests were conducted on soil samples mixed with varying percentage of jute fibre. The fibre percentages varied from $0.5 \%$ to $2 \%$. To understand the CBR values of jute fibre soil samples, the penetration values at $2.5 \mathrm{~mm}$ and $5 \mathrm{~mm}$ had to be observed. From figure 4, For $0.5 \%$ jute fibre, the CBR was $35.80 \%$ at $2.5 \mathrm{~mm}$ penetration; this is a positive improvement by an increase of $25.2 \%$ as compared to the CBR of unreinforced soil sample which was $28.19 \%$. For $1 \%$ jute fibre, the CBR was $47.23 \%$ at $5 \mathrm{~mm}$ penetration; here, the increase is exponential by about $24.83 \%$. For $1.5 \%$ jute fibre, the CBR was $40.14 \%$ at $5 \mathrm{~mm}$ penetration; as seen from the graph there is a slight reduction is CBR. For $2 \%$ jute fibre, the CBR was $45.45 \%$ at $5 \mathrm{~mm}$ penetration; again, there was an increase of about $11.68 \%$. Therefore from the graphs, it could be inferred that the maximum improvement in CBR was observed between $1 \%$ to $2 \%$ jute fibre as reinforcement.

\section{Conclusion}

By comparing the results of compaction (Figure 2), it could be observed that, at $0.5 \%$ to $1 \%$ of jute fibre, increment of MDD and OMC was achieved. but overall, it could be concluded that inclusion of jute fiber reduces the MDD and OMC. By comparing the results of direct shear test (Figure 3), it could be concluded that angle of internal friction and cohesion is achieved at the range of $1 \%$ to $2 \%$ of jute fibre. In direct shear strength, cohesion, increase with increasing fiber content until reaching a fiber content of $1 \%$, after which slight decrease in cohesion could be observed because fiber content tends to reduce fiber-reinforcing effects due to the replacement of soil particles by too many fibers By comparing the results of CBR (Figure 4) it was observed that maximum improvement in California 
Bearing Ratio values is observed between $1 \%$ to $2 \%$ of jute fibre as reinforcement. So the CBR value of the soil increases with the inclusion of jute fiber. Therefore it could be concluded that jute fibre could be used for soil stabilisation in the region under consideration.

\section{Acknowledgement}

Author thanks Sitaram Gawas, Shubham Gawas, Santosh Gawas, Pavan Singh \& Devraj Majik. Author also thanks Mr. Rajendra Hegde, Professor, Civil Engineering Department, Government Polytechnic Panjim, Goa.

\section{References}

Ahmad, F., Bateni, F., and Azmi, M. (2010). "Performance evaluation of silty sand reinforced with fibres." Geotext. Geomembr., 28(1), 93-99.

Anggraini, V. (2016). "Potential of coir fibres as soil reinforcement." Pertanika J. Schol. Res. Rev., 2(1), 95-106.

Babu, G.L.S. \& Vasudevan, A.K. (2008). "Strength and stiffness response of coir fibre reinforced tropical soils." Journal of Materials in Civil Engineering, 20(9):571- 577.

Chakraborty, T. K., and Dasgupta, S. P. (1996). "Randomly reinforced fly ash as foundation material." Proc., Indian Geotechnical Conf. IGC96, Indian Geotechnical Society, New Delhi, India, Vol. 1, 231235.

Donato, M., Foppa, D., Ceratti, J.A.P. \& Consoli, N.C. (2004)." Polypropylene fibers as reinforcement for geotechnical materials." Soils and Rocks, 27(2):161-179.

Han, J., Bhandari, A., and Wang, F. (2012). "DEM analysis of stresses and deformations of geogridreinforced embankments over piles.” Int. J. Geomech., 10.1061/(ASCE)GM.1943-5622.0000050, 340350 .

Kim, H., Won, M., and Jamin, J. (2015). "Finite-element analysis on the stability of geotextile tubereinforced embankments under scouring." Int. J. Geomech., 10.1061/(ASCE)GM.1943-5622.0000420, 06014019 .

Kumar, J.S. \& Sharma, P. (2018). "Geotechnical properties of pond ash mixed with cement kiln dust and polypropylene fiber." Journal of Material in Civil Engineering, 30(8):04018154.

Leshchinsky, D., Ling, H. I., and Perry, E. B. (1997). "Seismic design and performance of geosyntheticreinforced soil structures." Geotechnique, 47(5), 933-952. Li, C. (2005).

Maher, M., and Gray, D. (1990). "Static response of sands reinforced with randomly distributed fibers." J. Geotech. Engrg., 10.1061/(ASCE)0733 -9410(1990)116:11(1661), 1661-1677.

Maliakal, T. \& Thiyyakkandi, S. (2013). "Influence of randomly distributed coir fibers on shear strength of clay." Geotechnical and Geological Engineering, 31(2):425- 433.

Mohamed, A.E.M.K. (2013). "Improvement of swelling clay properties using hay fibers." Construction and Building Materials, 38:242-247.

Patra, C. R., Das, B. M., and Atalar, C. (2005). "Bearing capacity of embedded strip foundation on geogrid-reinforced sand.” Geotext. Geomembr., 23(5), 454-462.

Prabakar, J., and Sridhar, R. S. (2002). "Effect of random inclusion of sisal fibre on strength behaviour of soil." Constr. Build. Mater., 16(2), 123-131.

Segetin, M., Jayaraman, K., and Xu, X. (2007). "Harakeke reinforcement of soil-cement building materials: Manufacturability and properties.” Build. Environ., 42(8), 3066-3079.

Shwetha P. and Prasanna Kumar N. "Soil reinforcement using coconut shell ash; A case study of Indian soil." Journal of Civil Engineering and Construction, Vol. 6, 2017. 
Shwetha Prasanna. "Utilization of waste plastic shreds for stabilization of soil." Geotechnics for Transportation Infrastructure, 2018.

Tang, C.S., Shi, B. \& Zhao, L.Z. (2010). "Interfacial shear strength of fiber reinforced soil.” Geotextiles and Geomembranes, 28(1):54-62.

Yetimoglu, T., and Salbas, O. (2003). "A study on shear strength of sands reinforced with randomly distributed discrete fibers." Geotext. Geomembr., 21(2), 103-110.

Wang, Y., Guo, P., Shan, S., Yuan, H., and Yuan, B. (2016). "Study on strength influence mechanism of fiber-reinforced expansive soil using jute.” Geotech. Geol. Eng., 34(4), 1079-1088. 